\title{
Establish University Teachers Access System, Perfect Incentive Restraint Appointment Mechanism
}

\author{
Lanyong Zhang *, Sheng Liu and Kai Tian \\ College of Automation, Harbin Engineering University, Harbin 150001, China \\ *zlyalf@sina.com
}

Keywords: University Teachers; Access System; Appointment Mechanism

\begin{abstract}
To solve the current problems existing in teacher's construction of national universities, researchers proposed that human are the primary resource, and teacher's appointment process is essentially a process and purpose of human resource optimization. Teaching staff incentive and restraint mechanisms, through improving the personnel appointment and distribution system, create a good ecological development. Researchers have studied the university teacher recruitment selection system in United States and Germany, and proposed university teacher access system based on China's national conditions and the school situation, that is, only by establishing an effective incentive and restraint mechanism can the internal driving force of teaching staff and level promotion be produced, high-level universities be built, first-class talents be cultivatd, and first-class scientific research be created. The author implements the category and hierarchical management system, fully mobilizes the enthusiasm of the industry management department and employers, creates a good ecological environment for outstanding talents, and promotes the universities teaching establishment to develop in a healthy and sustainable way.1
\end{abstract}

\section{Introduction}

According to common experience of world-renowned universities, a highly qualified teaching staff is the key to core competencies and innovative talents of a university.

Teachers develop person with abilities. They play an important part in the national talent team, and they are the basic force to promote the scientific development of higher education. University personnel system is an important measure to motivate teachers to work for the national personnel training, scientific research, social services and cultural heritage. To build a strong human resources country, it is urgent to improve the overall quality of university teachers. To build an innovative-oriented country, it is urgent to establish an innovative and internationally competitive university teaching staff. University human resources are the primary resources, teacher's appointment is essentially a process and purpose of human resource optimization. Faced with the challenges of economic globalization and international competition, there is an urgent need for innovative university personnel system.

\footnotetext{
Zhang Lanyong (1983 -), male, engineering, Ph.D., lecturer and director of the laboratory. He is mainly engaged in the related research in the field of control science and engineering. Address: Automation institute of automation engineering, Harbin engineering university. Telephone: 045182588758, postcode: 150001.
} 
According to animal behavior theory, based on ability and level of university teaching staff, researchers can divide them into lions, wolves and sheep. Lions mean the outstanding intellects, just as the leaders, and a group of young academic leaders and backbones with innovative spirit and ability, and they also have a strong combat capability both in a team and individual. Wolves are the leader people. They are a number of young academic leaders with some innovative spirit and ability, and they have a strong team combat capability. Sheep, there are no capable person work as leaders, and they are lack of innovation and creative ability, and no team or individual combat capability, and their survival rely on the whole team.

To build a high level of teaching staff, the essence is to take the scientific development concept as guideline, development as the first prerequisite, and people-oriented as the core, take the comprehensive, coordinated and sustainable development as the basic requirements, integrated as a basic way to promote the university teaching staffs healthy development. The key is to find the internal driving force of its development, the incentive and restraint mechanisms. Only by continuing to improve personnel appointment and distribution system and create a good ecological development can researchers ensure the healthy development of university teaching staff.

\section{University Teacher Recruitment Selection System in USA and Germany}

Tenure system, university autonomy and academic freedom are known as the three cornerstones of American higher education. In 1940, the American Association of University Professor (AAUP) and the Association of American Universities (AACU) jointly issued the Declaration of Principles on Academic Freedom and Tenure, whose aim is to promote public's understanding and support to academic freedom and tenure systems, and to ensure consensus when universities implement these two programs. The definition about tenure in declaration was gradually widely accepted by the academia. After a certain trial period, teachers should have permanent and continuous lifelong tenure system, and the term can only be terminated for sufficient reason or unusual circumstances [1].

As well as the active effect, the tenure system also had some drawbacks. Since the 1990s, tenure system has been constantly questioned and criticized. Critics argue that tenure and academic freedom have no necessary links, because the Constitution ensures teachers' freedom of speech, including tenured and non-tenured. In the United States, half of teachers in colleges and universities are non-tenured, and this fact questions whether academic freedom and lifelong appointment system are inseparable. Opponents argue that the tenure system only emphasizes the obligation of teachers[2], but ignores the teachers' responsibility for the school, which is not conducive to the development of the university. Since the university could not dismiss mediocre teachers, it may protect teachers with low creative and reject teachers with high creative .As a result, it is hard to improve the overall quality of teachers. It is difficult for the university to make fair and reasonable and objective evaluation for teachers in short trial period. Due to the lack of incentive and restraint mechanisms, the tenured teachers may be lazy, lax, or lack of vitality and innovation, which leads to the overall decline in the quality of teachers.

Compare the tenure's negative impact of unfavorable factors to the important effect and significant meaning, and the negative impact is still insignificant. Thus, no major American university has canceled tenure system so far, but adopted a more moderate improvement measure against malpractice, such as, take the long-term contract instead of lifelong appointment, retrench the number of tenured faculty positions to improve standards, extend the probationary period, 
periodic review tenured teachers, that is, evaluation system after a lifetime appointment. In 1999, the American Association of University Professors issued a report tenured professor hired after review: Reaction AAUP, which proposed evaluation criteria for life after the review process of the appointment. By 2000, 37 states established a lifelong appointment appraisal system.

\section{Establish Access System for University Teachers}

Besides the general characteristic of labor, university teachers' labor also has the characteristic of transferring knowledge and scientific research. Therefore, the university teachers' profession is academic. The main features of the academic profession is exploration, autonomy and discipline. Academic research is human's exploration to the unknown, and a manner to grasp realm beyond their spirit. Human is always in active and conscious state during academic activities. Academic activities carry out in certain scope of knowledge, research disciplines and correlative knowledge drive scholars to determine the research direction and be engaged in scientific research. Academic research asks scholars for deep scientific knowledge, research capabilities, wisdom to explore the unknown, and devoted spirit to endure loneliness and poor[4].University teachers are experts both in disciplines and imparting knowledge and education. Only with a far-sighted strategic vision, can researchers be able to quickly capture new opportunities from scientific progress. The explorer, with development plan and a strategy to achieve their ideal dream, can make unremitting efforts and continue to create opportunities in their professional field and make their studies produce revolutionary changes, and finally cultivate the best students with courage to break and practice under the guidance of the idealist and explorer .

One of the main problems of university teacher appointment system is the lack of access system. In general, the university (college) graduates can directly enter the teaching staff (currently only the $\mathrm{PhD}$ graduates can enter the teaching staff in 985 universities and 211 Project). And as long as you enter the university, it seems that you have gotten a non-fixed term permanent positions and you can stay in school for life, unless you do not want to do it or you have made some serious mistakes[5]. The selection criterion for the lecturer in teaching, scientific research and the development potential is too vague. Establish university teachers' access system, and set up a trial period, so during the trial, teachers continue to improve themselves and exam themselves whether they are suitable for this post, at the same time, universities can have enough time to investigate teachers, then the two sides can reach a consensus.

In summary, establishing access system in the teachers' appointment of university is imperative. Researchers should take the experience of developed countries as reference, and take China's national conditions into consideration, and establish university teachers' access system with Chinese characteristics.

\section{Improve University Teacher Appointment System}

University teachers' appointment system is an effective means to optimize the allocation of human resources and improve employment benefits. It is the inherent requirements to deepen the reform of personnel system of universities, and an urgent need for income distribution system reform, also a method to achieve university human resources' self-management development and self-restraint under the guidance of the government. 
One of the important meanings of the appointment system in China is that a teacher's responsibility and treatment should be consistent with his post. The improvement of appointment system should create conditions for competition and selection mechanism and grading transfer mechanism.

One of the main problems of university teachers' appointment system is that the rights, obligations and responsibilities in the employment contract between school and teachers are not clear and specific. It cannot generate strong legal effect, to restrict the loose and weak mechanism. Teachers' appointment contracts are not standard or unified, and school and teachers' contract consciousness is not strong.

Since 2001, Harbin Engineering University has been adopted the teachers' appointment system reform, now researchers have entered the fourth round, and have a new round of reform of basic academic organization. The prototype of the teachers' appointment and evaluation system with Chinese characteristics has formed, and it also has the characteristic of American University teachers' lifetime appointment and evaluation system in a way. It makes great difference to promote the discipline and teaching staff construction, and enhance academic level and the quality of personnel training. However, in the evaluation system, there are still a lot of hard work about the evaluation criteria and evaluation system need to do.

\section{Better Cultural Ecology in University Improve the Incentive and Restraint Mechanisms}

As a unique form of organization with deep historical traditions and cultural heritage, university has a distinct cultural identity and spiritual character. It has the significant mission of cultural transmission and innovation, and plays an important role in university culture.

The internal integration mechanism in a complex organization always reflects in two dimensions, the structural integration and normative integration. Structural integration is mainly achieve by interactive contact between persons or groups in the organization, while normative integration comes from beliefs, attitudes and values shared by organization members[8].

Good cultural ecology can permeate through human's inner heart, in form of culture, and focus human's concept, and obtain group's sense of identity, finally create a domestic pluralistic values and behavior. It helps to eliminate the antagonism between members and enhance members' belongingness to school to highlight the nature and function of the university culture. Better university ecology is the competitive advantage in the world-class universities, foundation of university's core values, soil for university innovation, and the prerequisite for the university to lead and serve the community.

\section{Implement Category Management, and Inspire University Teachers' Enthusiasm}

Implementing the category management and hierarchical management system can fully mobilize the enthusiasm of the ind ustry management department and employers, and provide more space and opportunities for technical personnel in different majors to make contributions. The previous rating titles were divided into elementary, medium and high levels, the advantages are simple and easy to operate. But professional technical personnel are easy to have the feelings like the ship reaches the wharf and car reaches the station after they obtain senior posts, which let them have negative ideas and slack off towards the work, and count against with encouragement spirit and entrepreneurial development[9]. The implementation of ranking system makes different stages match different 
wages. Implement classification system and take the examinations and certificates as the requirement for seeking higher positions, like the nine grades allowance system in Tsinghua University. Deepening the titles reform should fully reflect certain features of the market economy, strengthen the appointment mechanism, and terminate the tenure system. Researchers should especially make progress in terms of promotion and demotion, and strengthen the competition and incentive mechanism to create an environment for the growth of outstanding talent and make a difference. Emphasize the management according to law, insist the Party's intellectuals policy and improve the level of administration according to law and scientific management of staff with titles.

\section{Conclusions}

Teaching staff is the primary productivity and resource in university's development. With economic globalization and university's internationalization, the establishment of access mechanism for university teachers and perfection of the appointment system are imperative. Only the effective incentive and restraint mechanisms can produce the internal driving force to build and improve teaching staff; only the teaching staff with high level can help to create a high-level of university, cultivate first-class talent and make first-class scientific research.

The key point to build a high level of teaching staff is to combine China's national conditions with the school's situation, seek for the internal driving force of personnel training, set up a perfect and scientific evaluation system and operational mechanism, mobilize the enthusiasm of all the teachers, create good ecology environment for outstanding talents, and make the teaching staff construction into a healthy sustainable development track.

\section{Acknowledgement}

The work was financed by Control Science and Engineering's Exploration and Practice (2011-16) in Heilongjiang Province, Exploration and Practice in University Teachers' Research and Achievement into Innovative Personnel Training's Practice Mechanism (JG2013010202) and Harbin Engineering University undergraduate education reform project Undergraduates' Technology Innovation and Small Business System's Research and Practice (JG2014BYB13). Planning Subject of Education Department of Heilongiiang Province (GBC1213103).

\section{References}

[1] Zhong Binglin. Attach great importance to the development of Higher Education Teachers [J].Chinese higher education, 2011 18:4-6

[2] Qiao Jianyong. Strengthen and improve the construction and management of teaching staff [J].Chinese higher education, 2011 (1):22-24.

[3] Fu daochun .Teachers' growth and development [M].Beijing, Education Science Press.

[4] Luo Teng, Li Jianchao, Li Qiaolan. Implement the Talent Strategy to promote the comprehensive development of the school career [J]. Chinese College Teachers Study, 2010 2:24-27. 
[5] Shen Chuanyuan, Wang Xingjie. Quality Construction and Countermeasures to academic leaders in Teaching and Research University [J] Zhejiang University of Technology (Social Sciences), $20112: 42-44$.

[6] Matheny K B. Ay cock D W, Pugh J L. Stress coping: A qualitative and qualitative synthesis with implications for treatment. Counseling Psychology[M] 1996, 14(5):499-549.

[7] Fontana D, Abouserie R. Stress Levels gender and personality factors in teachers. British Journal of Educational Psychology[M], 2003, 63(3): 261-270.

[8] Chen Yaping. Actively Implement the Three Core Strategy, and Continue to Strengthen High-Level Team Building Talents [J] Chinese College Teachers Study, 2010 6: 19-23

[9]Some Reflections About University Teachers' Titles System Reform [J] NAEA Sinica, 2010 5: $20-25$ 